\title{
El Arte de la llustración de Noticia
}

\author{
M. ${ }^{a}$ Dolores Bastida de la Calle *
}

La ruptura con la tradición que acompañó a la revolución industrial, y a las convulsiones de la Revolución francesa, resultó en el siglo XIx en una inmensa variedad de estilos y procedimientos artísticos. Pero aunque el XIX, un siglo marcadamente historicista, asumió todas las manifestaciones del pasado, los fenómenos artísticos marginales, donde el dominio de las convenciones era menor, adquirieron una relevancia especial. En el caso de la ilustración gráfica, ciertas innovaciones técnicas carentes de tradición - litografia, xilografia a la testa- vinieron a reforzar su atractivo.

Para la descripción del presente histórico, el siglo xIX encontró un eficaz instrumento expresivo, la ilustración de nolicia o de actualidad. Una ambición de la estética positivista era la consecución de la inmediatez, de unas formas de expresión directamente accesibles, que no apelaran al previo conocimiento de convenciones ${ }^{1}$. Esto incitó a visualizar y a revelar la realidad usando una factura de trazo simple, modesto, sin pretensiones, y una notación preocupada tan sólo por ceñirse a su modelo ${ }^{2}$. La ilustración de actualidad hizo posible alcanzar esa inmediatez.

La consecuencia fue que el artista reportero de los grandes semanarios se echó a la calle, en ciudades como Paris y Londres, a dibujar el discurrir de la vida urbana. La descripción de la miseria en los barrios bajos fue tema que suscitó interés inmediato; el primer gran ejemplo se remonta a 1850, cuando se publicaron en L'Illustration y The Illustrated London News una serie de estampas de Gavarni sobre Londres. En el último cuarto de siglo fue The Graphic la revista que puso mayor empeño

\footnotetext{
* Dpto. de Historia del Arte. UNED.

ROSEn, Charies y ZERNER, Henry, Romanticismo y realismo. Los mitos del arte del siglo xix. Madrid, Hermann Blume, 1988, pág. 49.

2 Jaccottet, Philippe, Le dessin trançais au xix Siècle. Laussanne, Mermod, 1948, pág. 17
} 
en esa descripción. Van Gogh, que admiraba extremadamente a Hubert Herkomer, Luke Fildes, y otros artistas del Graphic, soñó algún tiempo en realizar un trabajo semejante para este semanario londinense (fig. 1).

Es claro, sin embargo, que eran los acontecimientos caracterizados por una cierta instantaneidad -catástrofes, estallidos sociales, las batallas de un conflicto- los que mejor se acomodaban a la captación de lo inmediato. Asi, fue en la guerra civil americana (1861-1865), la primera relatada con ilustraciones grabadas inmediatamente después de las batallas, donde el periodismo gráfico alcanzó su madurez. Trenes y telégrafos acercaban el escenario de la guerra a las ya próximas Washington, Nueva York, Boston. Los lectores esperaban impacientemente noticias del conflicto, queriendo adivinar el ánimo de familiares o amigos en el frente.

Hubo una insaciable demanda de material gráfico, lo que exigió un continuo suministro de originales in situ. La urgencia de su trabajo, en particular en el caso de la noticia bélica, forzó a menudo al artista corresponsal al envio de croquis inacabados. Por otra parte, muchos originales fueron apuntes esbozados por aficionados, por ejemplo militares que tomaban parte en una contienda. En aquella época, poca gente pensó que toda esa obra fuera arte, y algunos editores participaron de ese juicio. Como señala J. Larson, el hecho de que croquis anteriores a 1900 sean hoy tan escasos, se debe en buena medida a una práctica rutinaria

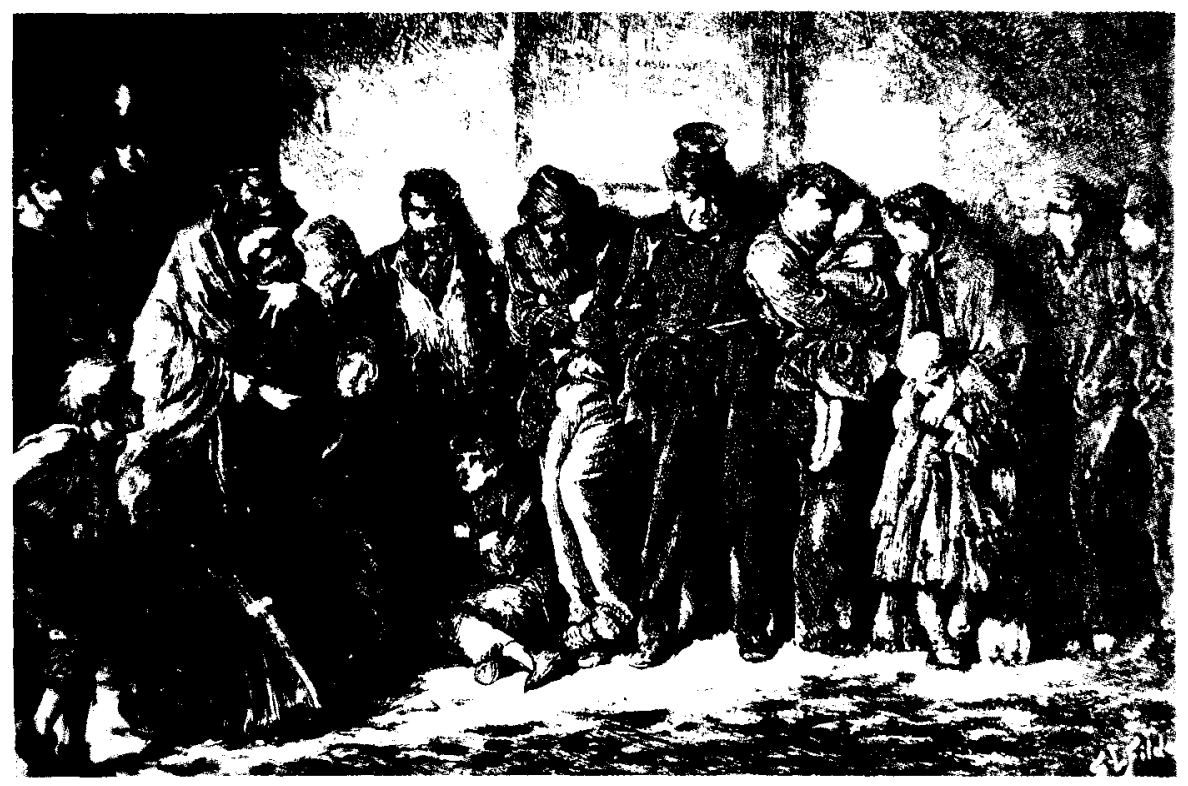

Fig. 1. FILDES, Luke: Houseless and Hungry. The Graphic, 4 de diciembre de 1869 
en redacciones de revistas: Una vez obtenida la estampa, eran destruidos para hacer sitio a otros ${ }^{3}$.

El mundo anglosajón ha mostrado un especial interés en el estudio de este "arte menor». En Inglaterra, se pueden encontrar artículos sobre la ilustración de noticia bélica del último tercio del siglo xix en diversas revistas de la época: The Idler, Windsor Magazine, Magazine of Art o lllustrated Naval and Military Magazine. En las últimas décadas, el trabajo del corresponsal artistico en la guerra de Secesión americana ha sido analizado por W. P. Campbell, Ph. van Doren, F. E. Ray, L. M. Starr, F. W. Thompson ${ }^{4}$. De cualquier modo, sólo en ciertos aspectos fué la ilustración de noticia un arte marginal; en otros, por el contrario, estuvo en la vanguardia de la evolución artística.

La captación de un momento histórico con sus peculiaridades, el registro de la actualidad, encontró en Baudelaire un firme entusiasta. Fue en un ensayo sobre Constantin Guys, publicado en Le Figaro en 1863, donde Baudelaire precisó su concepto de modernidad ${ }^{5}$. La admiración del poeta, como la del fotógrafo Nadar, por el dibujante, se remonta a los grabados que sobre la revolución de Paris, y la guerra de Crimea, habia publicado aquél en el Illustrated London News (fig. 2):

«Les mouvementes populaires... de 1848 avaient également fourni à $M$. G. une série de compositions pittoresques dont la plupart on été gravées par l'lllustrated London News".

Baudelaire habla, en su ensayo de la estética de lo transitorio, lo fugitivo, lo contingente. El interés positivista por la descripción de lo inmediato fomentó la natural aceptación del boceto, que los románticos habian exaltado. Ahora, con el dibujo de noticia, y especialmente el bélico, realizado usualmente al aire libre, al "vuelo», con trazo ágil, el boceto adquirió un

\footnotetext{
${ }^{3}$ LARSON, Judy L., American Illustration. 1890-1925. Calgary (Canadá), Glendow-Alberta Institute, 1986, pág. 31 .

${ }^{4}$ Campbell, W. P., The Civil War: Centennial Exhibition of Eyewitness Drawings. Washington D.C., National Gallery, 1961. Van Doren STERn, Philip, They were there. The Civil War in action as seen by its Combat Artists. New York, Crown Publishers, 1959. RaY, Frederic E., Alfred R. Waud. Civil War Artist. New York, Viking Press, 1974. StarR, Louis M., Bohemian Brigade. Civil War Newsmen in Action. New York, Alfred A. Knopt, 1954 y Reporting the Civil War. New York, Collier, 1962. Thompson, William Fletcher, The Image of War; the pictorial reporting of the American Civil War. New York, T. Yoseloff, 1960.

${ }^{5}$ Baudelaire, Charles, "Le peintre de la vie moderne", Le Figaro, Año 10, núms. 916-918 (1863).
} 


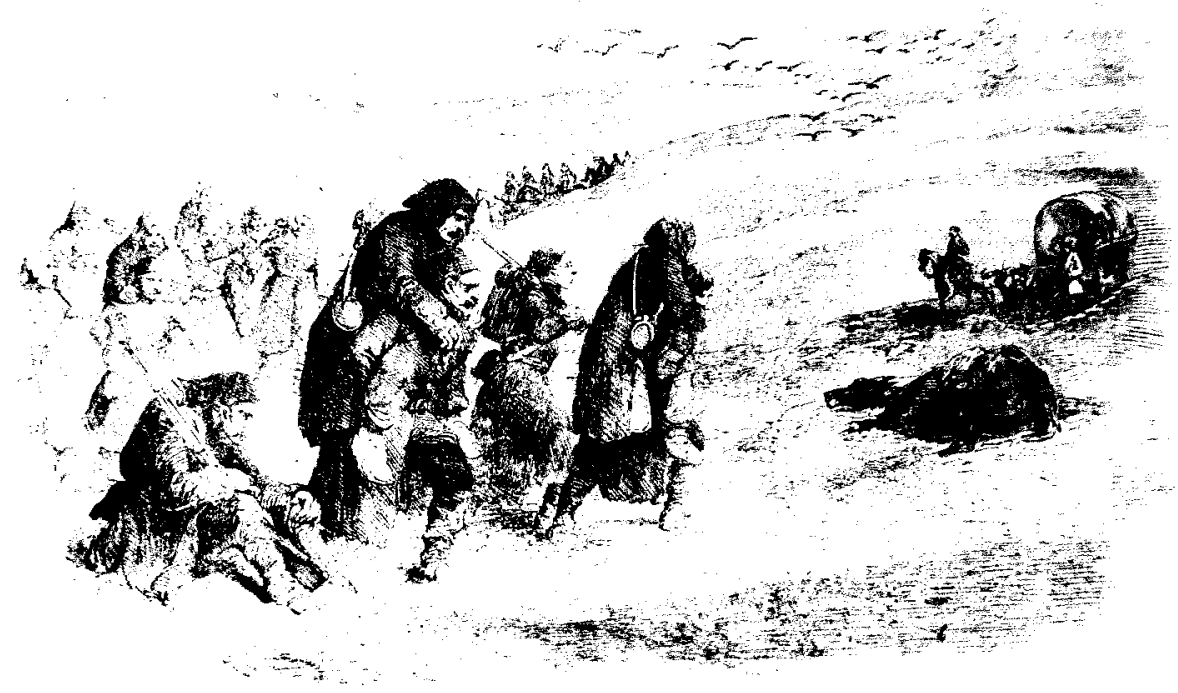

Fig. 2. GuYs, Constantin: Turks conveying the Sick to Balaclava. The Illustrated London News, 17 de marzo de 1855.

extraordinario desarrollo. Walter Benjamín ha señalado que, según Balzac, el arte del ilustrador periodístico estaba ligado al vistazo rápido ${ }^{6}$.

La etapa de máximo esplendor del periodismo gráfico, de 1870 a 1880 aproximadamente, coincide curiosamente con la eclosión del Impresionismo, alta pintura de rasgos muy consonantes. Obsérvese, sin embargo, que aquél antecedió a éste en dos décadas, y que los futuros impresionistas crecieron en los años cincuenta rodeados de imágenes difundidas por revistas como The Illustrated London News, L'Illustration, Le Monde IIlustré, lecturas duraderas de carácter familiar para amplias capas educadas o semieducadas de la población europea de la época (fig. 3). Se ha señalado que la búsqueda de la espontaneidad, el gusto por lo transitorio, ciertos artificios gráficos del dibujo de actualidad, tuvieron una influencia fecunda en el nacimiento del Impresionismo ?. En la escena de una tarde de concierto en el jardin de las Tullerias, pintada por Manet en 1862 o en "La plage" de Eugène Boudin (1867), se está ya muy próximo

${ }^{6}$ Herbert, Robert L., El Impresionismo. Arte, ocio y Sociedad. Madrid, Alianza, 1989, pág. 43; Benjamin, Walter, Poesia y Capitalismo. lluminaciones II. Madrid, Taurus, 1990, pág. 56.

"ISAACSON, Joel, «Impressionism and Journalistic lliustration», Arts, núm. 56, (1982), págs. 95-115. 


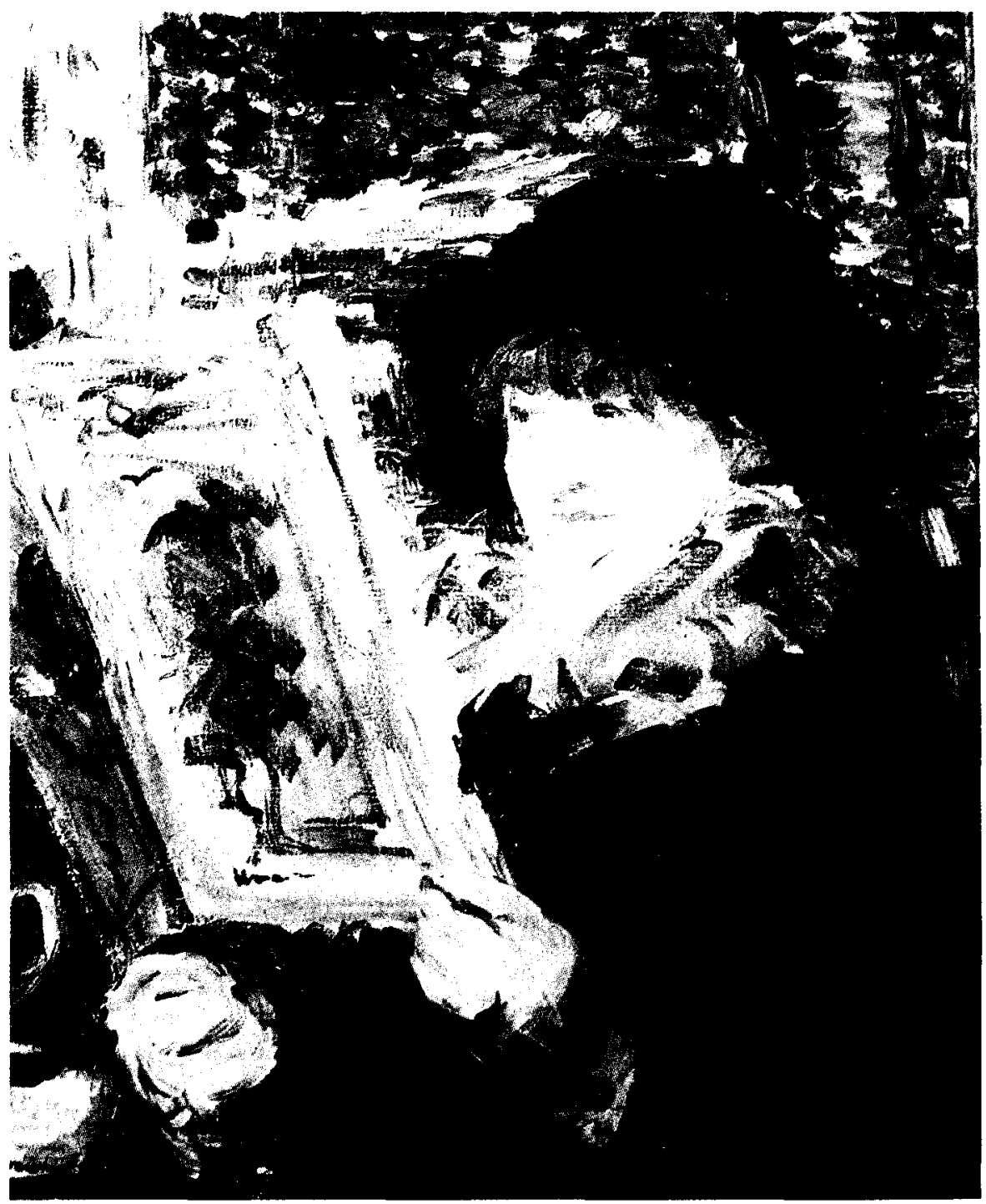

Fig. 3. MANET, Edouard: Mujer leyendo; la Lectura de la Revista, 1879. Art Institute of Chicago. 
a cierta estética «fotográfica» de aquel arte. También en España se ha señalado que la estampa seria de La llustración Española y Americana enlaza directamente con la pintura naturalista e impresionista que empieza a dominar a finales de siglo ${ }^{8}$.

De hecho, en los editoriales de sus primeros años, algunas revistas percibieron muy claramente la distancia que separaba sus estampas de noticia, de los grabados intemporales que publicaban sus antecesores y coetáneos, los Magazines. El 4 de marzo de 1843, el editor J. J. Dubochet, al presentar L'lllustration, se preocupó de aclarar cuidadosamente a sus lectores que iba a cubrir un campo muy diferente:

«Pensera-t-on que nous allons être reduits aux monuments, aux sujets généraux d'instruction, au rétrospectif, et qu'en définitive nous ne serons différenciés que par les dimensions du format des recueils du même genre qui existen déjà? II nous est trop facile de répondre» ${ }^{\text {. }}$.

Se estaba aqui ya lejos del ideal de estampa costumbrista de la época romántica.

Ciertamente ha habido antecedentes de la funcionalidad y la agilidad que confirieron al periodismo gráfico su carácter artisticamente peculiar. Se ha observado esa frescura en la captación de lo vivo incluso en ciertas anotaciones dibujadas en códices medievales ${ }^{10}$. Pero en el registro pictórico de revista, ese carácter es su esencia misma. Cada ilustración comienza a ser vivida en forma de sketch y es alli, en la rapidez de la ejecución y en el arrebato del lápiz, sin "que las órdenes del espíritu sean alteradas por las vacilaciones de la mano" ", donde se produce la impresión de ligereza. Van Gogh, que en las Cartas a Théo expresó repetidamente su admiración por la xilografía de revista, escribió, sobre la plasmación de vida y movimiento, que «es precisamente el hecho de tenerse, lo que debe resultar ya desde el primer croquis" "2.

Se ha sugerido, sin embargo, que las estampas, tal como aparecian publicadas, en nada se parecen a los croquis originales. Esto es, en muchos casos, correcto. En condiciones de extrema urgencia, el artista co-

${ }^{8}$ Bozal, Valeriano, La llustración gráfica del siglo xix en España. Madrid, Comunicación, 1979, pág. 182.

'L'llustration, Vol. 1, núm. 1, (1843), pág. 1.

10 Pérez Sánchez, Alfonso, Historia del dibujo en España. De la Edad Media a Goya. Madrid, Cátedra, 1986, págs. 107 y 108.

1 Baudelaire, Ch., Op. cit.

12 Van Gogh, Vincent, Cartas a Théo. Barcelona, Labor, 1987, pág. 179. Introducción de Fayad Jamis. 
rresponsal llegó a anotar en su boceto detalles a rellenar por un dibujante de estudio, en particular en el caso de elementos arquitectónicos repetitivos. Mason Jackson, redactor jefe de arte del Illustrated London News durante casi medio siglo, señaló casos extremos en los que el trabajo en estudio modificó sustancialmente el original tomado in situ por el corresponsal ${ }^{13}$. Un periódico no era una revista de arte y se sacrificaba todo por publicar un grabado a tiempo. Ocasionalmente se llegó a trabajar sobre una parte reducida del croquis, que era redibujada totalmente; o bien figuras, paisaje y arquitectura se encargaban a diferentes dibujantes. Ivins ha recordado que los originales, que Guys enviaba desde Crimea, eran retocados en Londres por Gavarni ${ }^{14}$. En España A. Gallego ha insistido en el carácter de tercera o cuarto mano de la imagen que llegaba al público.

Esta critica, no obstante, es sólo en parte correcta. Cuando le era posible, el artista elaboraba y completaba el material reunido en su block de notas, que él mismo a veces llegó a pasar a la madera. Este fue el caso de Winslow Homer en la guerra de Secesión americana, volviendo del frente a Nueva York, y al taller del Harper's Weekly; el de Daniel Vierge, registrando la Comuna de París en Le Monde Illustré; el de Arthur B. Houghton, en sus crónicas de América para el Graphic. En tales casos, y en otros muchos semejantes, lo que nos ofrece la estampa, salvo por el trabajo del grabador, es obra exclusiva de quien realizó el sketch in situ. En España, el ejemplo más significativo es el de José Luis Pellicer, quien se opuso a que su obra para La llustración Española y Americana, bien bocetos, bien dibujos acabados, fuese manipulada por dibujantes de estudio ${ }^{15}$. El Illustrirte Zeitung, de Leipzig, en leyendas de estampas muy terminadas, señala unas veces que proceden de bocetos y otras de dibujos, realizados en uno y otro caso por corresponsales; sólo en el primero intervino un artista de gabinete reelaborando el original.

En las revistas anglosajonas no existió una política definida sobre el reconocimiento de autoría. Los grabados firmados por un reportero gráfico son escasos, y se pueden encontrar en el Graphic y el Harper's, pero no en el I/lustrated London News. En L'/l/ustration las estampas siempre llevan la firma o la inicial de un dibujante, la mayoría de las veces el corresponsal, cuyo dibujo no fue modificado en estudio, lo que se refleja

\footnotetext{
13 JaCkson, Mason, The Pictorial Press: Its origins and progress. London, Hurst and Blackett, 1985 , págs. 317 y 320 .

14 IVIns, William M., Imagen impresa y conocimiento. Análisis de la imagen prefotográfica. Barcelona, Gustavo Gili, 1975, pág. 147.

${ }^{15}$ Bastida de la Calle, M. ${ }^{a}$ Dolores, "José Luis Pellicer, corresponsal artistico en la última guerra carlista", Espacio, Tiempo y Forma, Serie VII, núm. 2, (1989), págs. 343-375.
} 
a menudo en una menor calidad de las ilustraciones respecto de otras revistas. En el otro extremo, Le Monde Illustré reconoció sistemáticamente tanto el croquis del corresponsal como el trabajo del artista de gabinete. En menor medida, en casi todas las revistas se encuentran ejemplos en los que el artista de gabinete impone su autoria, firmando en la estampa (F. Regamey en el Illustrated London News, Kauffmann en L'illustration, J. Nash en el Graphic...).

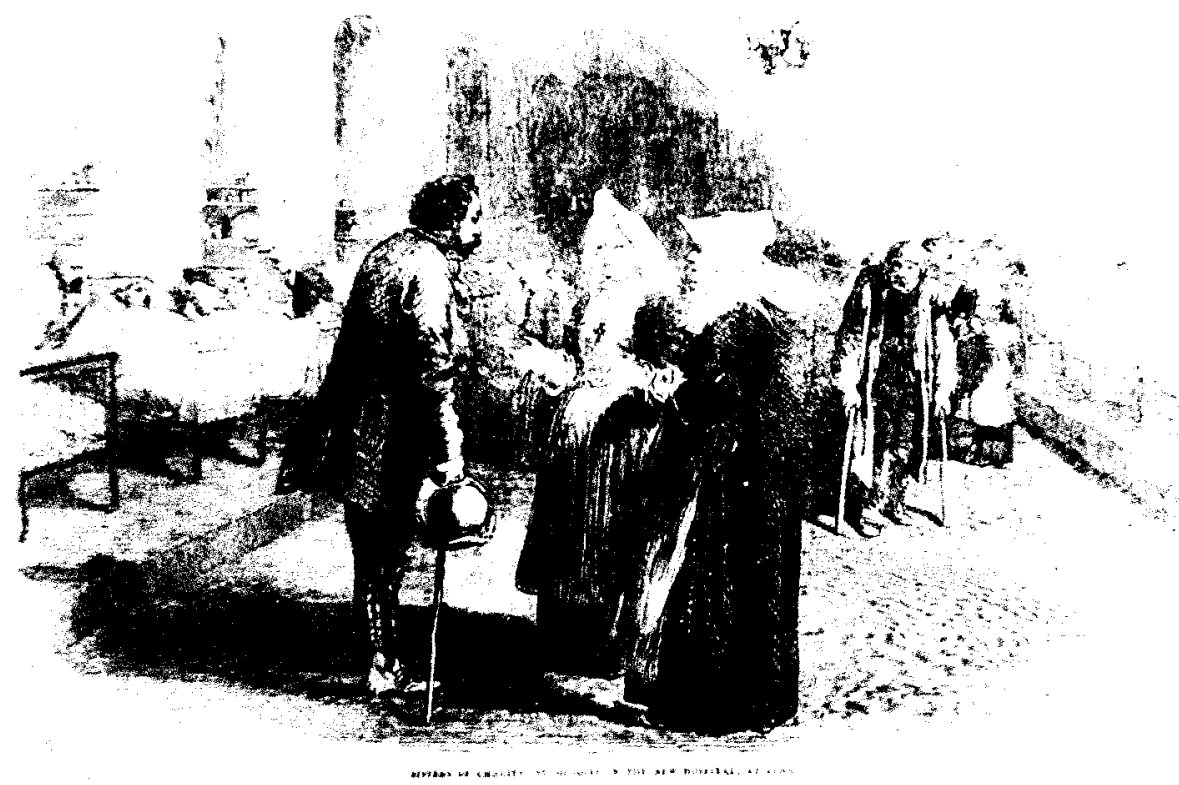

Fig. 4. GuYs, Constantin: Sisters of Charity (St. Benoit) in the New Hospital, at Pera. The Illustrated London News, 30 de noviembre de 1854.

Es cierto, sin embargo, que en un gran número de grabados no es posible una atribución clara de autor. La situación se debe, sin duda, al carácter semi-industrial del periodismo gráfico y se parece en nuestro si- 


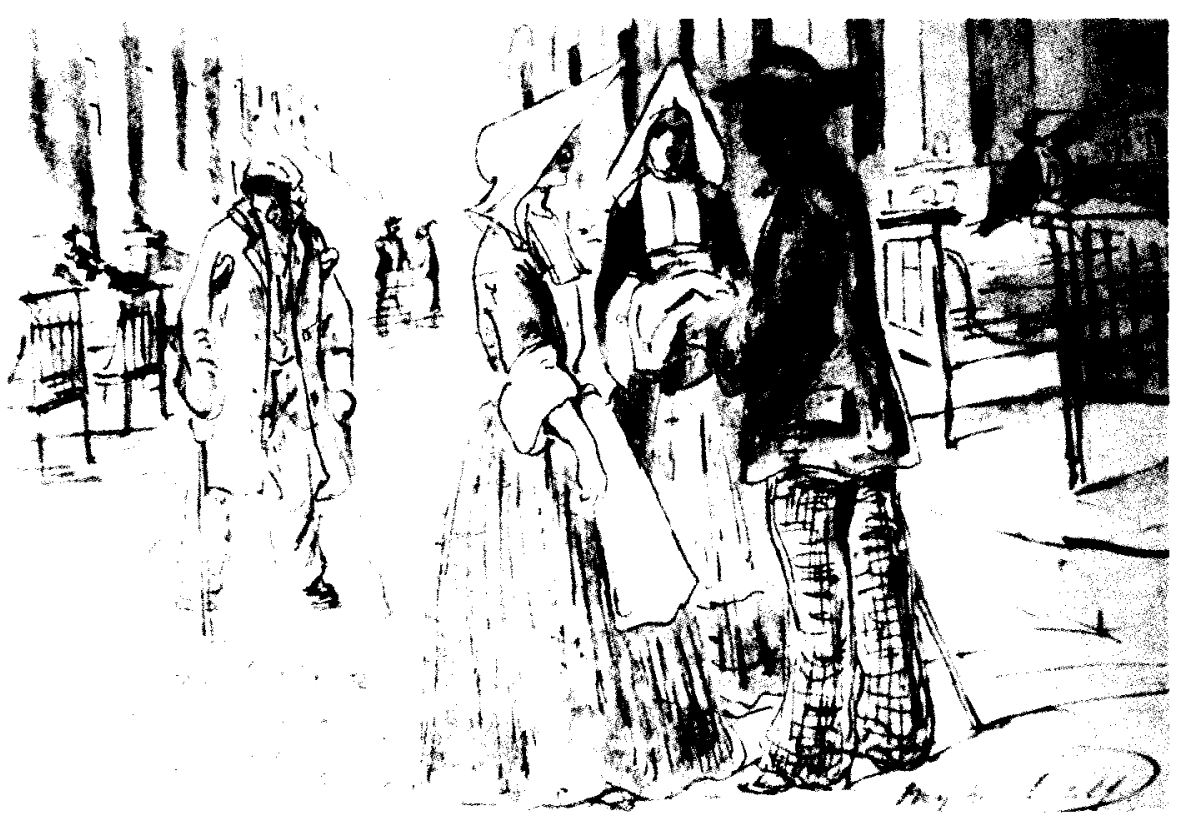

Fig. 5. Gurs, Constantin: Las Hermanas de la Caridad en el Hospital de Pera, 1854. Musée des Arts Décoratifs, Paris.

glo al caso del cine, donde el resultado final surge de la labor conjunta de director, guionista, cámara, actores... y en América el mismo productor. En cierta manera la crítica a la documentación gráfica de actualidad, como la crítica al cine, recuerda la estéril polémica clásica sobre la pureza artistica relativa de poesia y pintura. Quizá convendria recordar que cuando Baudelaire escribió su ensayo en elogio de Constantin Guys en 1863. tenia a la vista las estampas del Illustrated London News y muchos de los originales correspondientes, regalados por Nadar ${ }^{16}$ (figs. 4 y 5 ).

${ }^{16}$ La mayor parte de los croquis bélicos preservados corresponden a la guerra de Secesión americana y a la obra de Guys en Crimea. Véase Duflo, Pierre, Constantin Guys. Fou de dessin, grand reporter 1802-1892. Paris, Arnaud Seydoux, 1988. 
